\title{
Efecto de la suplementación de grasas sobre las concentraciones séricas de progesterona, insulina, somatotropina y algunos metabolitos de los lípidos en ovejas Pelibuey
}

\author{
Effect of fat supplementation on serum concentrations of progesterone, insulin, growth hormone \\ and some lipid metabolites in Pelibuey ewes \\ JL Espinoza ${ }^{a^{*}, \text { A Palacios }}{ }^{\text {a }}$, R Ortega ${ }^{\mathrm{b}}$, A Guillén ${ }^{\mathrm{a}}$ \\ aDepartamento de Zootecnia, Universidad Autónoma de Baja California Sur. Carretera al Sur, km 5,5, \\ CP 23080, La Paz, B.C.S., México. \\ ${ }^{\text {b} C e n t r o ~ d e ~ I n v e s t i g a c i o n e s ~ B i o l o ́ g i c a s ~ d e l ~ N o r o e s t e ~(C I B N O R), ~ L a ~ P a z, ~ B . C . S ., ~ M e ́ x i c o . ~}$
}

\begin{abstract}
SUMMARY
In this study, multiparous Pelibuey ewes were used to determine the influence of calcium soap of fatty acids (CSFA) and bovine fat in the diet on serum concentrations of insulin, somatotropin, progesterone and lipid metabolites (total cholesterol, high and low density lipoproteins and triglycerides). Ewes ( $\mathrm{n}=6$ per group) were assigned randomly to a diet that contained 1.5\% CSFA (CS) or 1.2\% bovine fat (S), or to a control diet (T) with no additional fat. The diets were provided during 75 days. Weight gain among treatments was similar $(\mathrm{P}>0.05)$. The concentrations of lipid metabolites and progesterone were not affected by the diet $(\mathrm{P}>0.05)$. Insulin concentration was higher $(\mathrm{P}<0.01)$ in ewes that consumed additional fat and higher $(\mathrm{P}<0.001)$ in $\mathrm{S}$ than in $\mathrm{T}$ and CS. The somatotropin concentration was lower $(\mathrm{P}<0.05)$ in ewes of groups $\mathrm{CS}$ and $\mathrm{S}$ than in $\mathrm{T}$. The number and size of pulses of somatotropin among treatments were similar $(\mathrm{P}>0.05)$. In conclusion, bovine fat and calcium soap of fatty acids incorporated in the diet of Pelibuey ewes, in the indicated proportions, did not affect weight gain, progesterone concentration or lipid metabolites, but the bovine fat increased the serum concentration of insulin, reducing that of somatotropin.
\end{abstract}

Palabras clave: ovejas Pelibuey, suplementación de grasa, hormonas, metabolitos de lípidos.

Key words: Pelibuey ewes, fat supplementation, hormones, lipid metabolites.

\section{INTRODUCCION}

La manera de actuar de las grasas en los procesos reproductivos no es clara y una teoría se apoya en que las dietas hiperlipídicas proporcionadas a rumiantes casi siempre provocan un incremento en los niveles sanguíneos de colesterol total (COL), lipoproteínas de alta densidad (LAD) y de lipoproteínas de baja densidad (LBD); la importancia de las LAD así como de LBD radica en que en la mayoría de las especies las lipoproteínas son la fuente principal de COL para la síntesis de hormonas esteroides (Grummer y Carroll 1988).

Wehrman y Williams (1989) encontraron que cuando se suplementó a vacas recién paridas y vaquillas vírgenes con $8 \%$ de extracto etéreo se elevaron los niveles de COL y de LAD tanto en el suero sanguíneo como en el líquido folicular. Hightshoe y col (1991) observaron mayores niveles séricos de COL en animales suplementados con grasas protegidas de la digestión en el rumen en forma de jabones de calcio de ácidos grasos (JCAG) que en las vacas testigo durante el periodo posparto. En ovejas Pelibuey se ha observado que la inclusión de JCAG en la

\footnotetext{
Aceptado: 31.10.2007.

* Nicolás Bravo \# 419, entre Guillermo Prieto y Serdán, Colonia Centro, CP 23000, La Paz, B.C.S., México; jlvilla@uabcs.mx
}

dieta incrementa las concentraciones séricas de COL y de LAD (Espinoza y col 1997, Espinoza y col 1998).

La mayoría de los estudios han demostrado una relación positiva entre la concentración sérica tanto de COL como de LAD y LBD sobre la secreción de progesterona (Espinoza y col 1995). Las concentraciones séricas de progesterona en vacas para carne (Hawkins y col 1995) y en ovejas Pelibuey (Espinoza y col 1997) fueron mayores en los animales que consumieron JCAG que en los testigo.

La suplementación de diferentes tipos de ácidos grasos en la dieta ha incrementado los niveles séricos de insulina en rumiantes; dicha hormona ejerce una acción directa sobre las células de la membrana granulosa, acción que puede ser requerida para el desarrollo de un potencial esteroidogénico óptimo (Thomas y col 1997). La secreción de progesterona bajo el estímulo de la insulina se ha demostrado tanto en células de la granulosa de cerdas como en células de la granulosa de vacas y células de la teca porcina (Langhout y col 1991).

La relevancia fisiológica de la acción de la somatotropina sobre la esteroidogénesis folicular no se conoce con claridad; sin embargo, sí está claro que dicha hormona influye tanto en la esteroidogénesis folicular como en la foliculogénesis a través de su estímulo sobre la producción de insulina y del factor de crecimiento similar a la insulina tipo I (Gong y col 1993). 
Tomando en cuenta estas consideraciones, el objetivo del presente estudio fue evaluar el efecto de diferentes fuentes de grasa sobre la concentración sérica de insulina, somatotropina y progesterona, así como sobre algunos metabolitos sanguíneos como el COL total, LAD, LBD y triglicéridos (TG) utilizando ovejas Pelibuey como modelo experimental, bajo la hipótesis de que el consumo de JCAG y el consumo de grasa de bovino afectan los niveles séricos de las hormonas señaladas y de los compuestos involucrados en el metabolismo de los lípidos, destacados con anterioridad.

\section{MATERIAL Y METODOS}

\section{DESCRIPCION DEL AREA DE ESTUDIO}

El presente trabajo fue desarrollado en la posta zootécnica de la Universidad Autónoma de Baja California Sur, en La Paz, B.C.S., México, situada en las coordenadas geográficas $24^{\circ} 06^{\prime} 0$ " $\mathrm{N}$ y $110^{\circ} 19^{\prime} 00^{\prime \prime} \mathrm{O}$, a 33 metros sobre el nivel del mar. Las temperaturas medias mensuales oscilan entre 27 y $34^{\circ} \mathrm{C}$. La precipitación media anual es de 195,4 mm (DGTENAL 1980).

\section{DISEÑO DE LOS TRATAMIENTOS}

Se utilizaron 18 ovejas Pelibuey multíparas sin cría, de $51 \pm 1,8 \mathrm{~kg}$ peso vivo, las cuales fueron asignadas aleatoriamente $(n=6$ ovejas por grupo) para recibir $1 \mathrm{~kg} /$ oveja/día de una dieta testigo $(\mathrm{T})$ consistente en heno de alfalfa y grano de maíz molidos, o dietas basadas en los mismos ingredientes pero que contenían $1,5 \%$ de una grasa comercial en forma de jabones de calcio de ácidos grasos (JC) o 1,2\% de grasa de bovino (S) mezcladas cada una de ellas en una ración integral. Las dietas fueron isocalóricas $(\mathrm{EM}=2 \mathrm{Mcal} / \mathrm{kg}$ ), su contenido de PC fue de $10,6 \%$ en $\mathrm{T}$ y $10,5 \%$ en JC y S y la concentración total de grasa de $2,5 \%$ en $\mathrm{T}$ y de 3,5\% en JC y S. La composición química de las dietas se determinó de acuerdo al AOAC (1995) y la EM fue calculada de las tablas de la NRC (1985).

Los animales se mantuvieron en corrales individuales y se les ofreció el alimento dos veces al día (07:00 y 19:00 horas). Las ovejas fueron observadas dos veces al día (06:00 y 18:00 horas) para la detección de estros hasta finalizar el estudio, utilizando para ello un carnero intacto con arnés. Solamente se utilizaron animales con más de tres ciclos estrales regulares (17 a 21 días) consecutivos antes de iniciar el consumo de las dietas experimentales, las cuales fueron proporcionadas durante un periodo de 75 días. A partir de los 30 días de haber iniciado el consumo de las dietas experimentales y considerando una adaptación completa a las mismas, las ovejas fueron tratadas con un implante subcutáneo conteniendo $3 \mathrm{mg}$ de Norgéstomet [NOR; Sanofi Animal Health, Inc. (Overland Park, KS)] mantenido durante 10 días y una inyección intramuscular de NOR (1,5 mg) y valerato de estradiol (2,5 mg) el día en que se colocó el implante de NOR. Se aplicó una inyección intramuscular de $10 \mathrm{mg}$ de prostaglandina $\mathrm{F}_{2} \alpha$ (Lutalize ${ }^{\circledR}$, Pharmacia \& Upjohn Co., Kalamazoo, MI) 48 horas antes de retirar el implante de NOR. Todas las ovejas manifestaron estro dentro de un periodo de 48 horas posteriores a la remoción del implante subcutáneo. El peso corporal de los animales fue registrado a intervalos de 14 días durante todo el periodo experimental.

\section{MUESTREOS SANGUINEOS Y TECNICAS DE LABORATORIO}

En el día 1 del ciclo estral sincronizado (día $0=$ manifestación del estro), el alimento que normalmente se ofrecía por la tarde se proporcionó a las 22:00 horas, se permitió a las ovejas consumirlo durante 1 hora y posteriormente se retiraron los residuos del comedero. A partir de las 8 horas después de haber retirado el alimento del comedero, se colectaron muestras de sangre $(10 \mathrm{ml})$ en tubos vacutainer sin anticoagulante mediante punción de la vena yugular a intervalos de 2 horas durante un periodo de 14 horas. Las muestras de sangre se refrigeraron a $4{ }^{\circ} \mathrm{C}$, se centrifugaron (1500 x $g$ durante 15 minutos) dentro de los 60 minutos posteriores a la colección y se almacenaron a $-20{ }^{\circ} \mathrm{C}$ hasta que las concentraciones de insulina (Sanson y Hallford 1984) y somatotropina (Hoefler y Hallford 1987) fueron determinadas por radioinmunoanálisis. Los coeficientes de variación intraensayo para insulina y somatotropina fueron de 12,1 y $15,5 \%$, respectivamente.

En el día 9 del ciclo estral sincronizado se colectó una muestra de sangre $(10 \mathrm{ml})$ de cada animal. Estas muestras fueron obtenidas y almacenadas de acuerdo al procedimiento descrito anteriormente. El suero colectado en el día 9 del ciclo estral, se almacenó en tubos de plástico a $-20{ }^{\circ} \mathrm{C}$ hasta que los metabolitos de lípidos (COL, LAD, LBD y TG) fueron cuantificados por medio de procedimientos enzimáticos automatizados. El COL se determinó en el suero después de haber sido hidrolizado y oxidado enzimáticamente. En el proceso de oxidación se produjo $\mathrm{H}_{2} \mathrm{O}_{2}$. En presencia de peroxidasa, reaccionando con 4-amino-antipirina y fenol, se transformó en un colorante de quinonimina (MerckMéxico, S. A.). Las LAD se separaron de los quilomicrones, lipoproteínas de muy baja densidad, y de las LBD mediante la adición de un reactivo precipitante al suero. Después de la centrifugación, el contenido de COL y la fracción de LAD permanece en el sobrenadante y se determinó por el método colorimétrico enzimático utilizando colesterol estearasa, colesterol oxidasa, peroxidasa y el cromógeno 4-aminofenasona/fenol (Sera-Pak, Ames Division, IA). Las LBD se determinaron por diferencia del COL y LAD. El método colorimétrico enzimático para la determinación de TG está basado en el principio de que el glicerol liberado de la hidrólisis de TG por la lipoproteína lipasa es convertido por la gliceroquinasa a glicerol-3-fosfato, el cual es oxidado por la glicerofosfato oxidasa a dihidroxiacetona fosfato $\mathrm{y}_{2} \mathrm{O}_{2}$. En presencia de peroxidasa, el $\mathrm{H}_{2} \mathrm{O}_{2}$ oxida el cromógeno 4-aminofenasona/N-etil-N-(3-sulfopropil)- 
m-anisidina a un compuesto de color violeta (Sera-Pak, Ames Division, IA).

Las muestras de suero sanguíneo obtenidas en el día 9 del ciclo estral sincronizado (fase lútea del ciclo) también se utilizaron para determinar la concentración de progesterona mediante radioinmunoanálisis usando para ello un kit comercial (Diagnostic Products, Los Angeles, CA). El coeficiente de variación intraensayo fue de 4,7\%. Los animales se siguieron observando para la detección de estros después del último muestreo sanguíneo, con el fin de constatar la persistencia de ciclos estrales regulares.

\section{ANALISIS ESTADISTICO}

El peso corporal, metabolitos de las grasas, número de pulsos de somatotropina, amplitud de dichos pulsos y concentración sérica de progesterona se analizaron con el paquete estadístico SAS (SAS 1989), mediante el procedimiento GLM, de acuerdo al siguiente modelo:

$$
\mathrm{y}_{\mathrm{ij}}=\mu+\tau_{\mathrm{i}}+\varepsilon_{\mathrm{ij}}
$$

Donde:

$\mathrm{y}_{\mathrm{ij}}$ corresponde, según se trate, al peso corporal, metabolitos de las grasas, número de pulsos de somatotropina, amplitud de los pulsos de somatotropina, o concentración sérica de progesterona;

$\tau_{\mathrm{i}}$ es el efecto del i-ésimo tratamiento; $\mathrm{y}$

$\varepsilon_{\mathrm{ij}}$ es el error experimental.

La ocurrencia del pulso fue considerada cuando el valor de una muestra (pico) excedió al valor de la muestra precedente (basal) en al menos cuatro veces el coeficiente de variación intraensayo; la amplitud de los pulsos se determinó restando al valor del pico la concentración basal previa (Walters y col 1984).

Las concentraciones séricas promedio de insulina y somatotropina se analizaron a través de un diseño de parcelas divididas en el tiempo. Los términos incluidos en el modelo fueron tratamiento, animal dentro de tratamiento, tiempo de muestreo y la interacción tratamiento x tiempo. Cuando la interacción no resultó significativa únicamente se reportaron los efectos principales. El efecto principal de la parcela completa fue evaluado usando al animal dentro de tratamiento como término específico del error. Los efectos de las subparcelas tiempo y tratamiento $\mathrm{x}$ tiempo fueron probados usando el error residual. Se utilizó el procedimiento GLM del SAS (SAS 1989) de acuerdo al modelo que se describe a continuación:

$$
\mathrm{y}_{\mathrm{ijkl}}=\mu+\tau_{\mathrm{i}}+\mathrm{A}_{\mathrm{j}(\mathrm{i})}+\mathrm{B}_{\mathrm{k}}+(\mathrm{B} \tau)_{\mathrm{ik}}+\varepsilon_{\mathrm{ijkl}}
$$

Donde:

$\mathrm{y}_{\mathrm{ijkl}} \quad$ corresponde a la concentración sérica de insulina o somatotropina, según se trate;

$\tau_{\mathrm{i}} \quad$ es el efecto del i-ésimo tratamiento;
$\mathrm{A}_{\mathrm{j}(\mathrm{i})} \quad$ es el efecto del j-ésimo animal dentro del i-ésimo tratamiento;

$B_{k} \quad$ es el efecto del k-ésimo tiempo;

$(\mathrm{B} \tau)_{\mathrm{ik}}$ es la interacción tiempo-tratamiento;

$\varepsilon_{\mathrm{ijkl}} \quad$ es el error experimental.

En todos los casos, las variables cuyo análisis de varianza dio como resultado diferencias significativas $(\mathrm{P}<0,05)$ fueron sometidas a una prueba de comparación de medias, utilizándose la prueba de contrastes ortogonales $(95 \%)$. Todos los resultados son presentados como medias aritméticas con el error estándar (EE) correspondiente.

\section{RESULTADOS}

El peso inicial y la ganancia de peso por día fueron similares $(P>0,05)$ entre tratamientos (cuadro 1).

No se observaron diferencias $(\mathrm{P}>0,05)$ entre T, JC y $\mathrm{S}$ para ninguno de los metabolitos de los lípidos que fueron analizados (cuadro 2).

Cuadro 1. Medias ( \pm EE) para el peso inicial (PI), peso final (PF) y la ganancia de peso por día (GPD) en ovejas Pelibuey, por tratamiento.

Average ( \pm SE) initial weight (PI), final weight (PF) and

\begin{tabular}{|c|c|c|c|c|c|}
\hline \multirow[b]{2}{*}{ Variable, $\mathrm{kg}$} & \multicolumn{3}{|c|}{ Tratamiento $^{1}$} & \multicolumn{2}{|c|}{$\begin{array}{c}\text { Contraste }^{2}- \\
\text { valor de la P }\end{array}$} \\
\hline & $\mathrm{T}$ & $\mathrm{JC}$ & $S$ & 1 & 2 \\
\hline PI & $51 \pm 1,8$ & $51 \pm 1,8$ & $51 \pm 1,8$ & 0,99 & 0,99 \\
\hline PF & $52 \pm 0,6$ & $53 \pm 0,6$ & $53 \pm 0,6$ & 0,91 & 0,82 \\
\hline GPD & $0,013 \pm 0,008$ & $0,021 \pm 0,008$ & $0,022 \pm 0,008$ & 0,77 & 0,96 \\
\hline
\end{tabular}
weight gain per day (GPD) in Pelibuey ewes, by treatment.

$1 \mathrm{~T}=$ dieta $\sin$ grasa adicional; $\mathrm{JC}=$ dieta con $1,5 \%$ de jabones de calcio de ácidos grasos; $\mathrm{S}=$ dieta con $1,2 \%$ de grasa bovina.

2 Contrastes: 1) T vs JC + S; 2) JC vs S.

Cuadro 2. Medias ( \pm EE) para la concentración sérica de metabolitos de los lípidos en ovejas Pelibuey, por tratamiento.

Average $( \pm$ SE) serum concentrations of lipid metabolites

\begin{tabular}{|c|c|c|c|c|c|}
\hline \multirow[b]{2}{*}{ Metabolito $^{3}, \mathrm{mg} / \mathrm{dl}$} & \multicolumn{3}{|c|}{ Tratamiento $^{1}$} & \multicolumn{2}{|c|}{$\begin{array}{c}\text { Contraste }^{2} \text {-valor } \\
\text { de la } \mathrm{P}\end{array}$} \\
\hline & $\mathrm{T}$ & $\mathrm{JC}$ & $S$ & 1 & 2 \\
\hline $\mathrm{COL}$ & $103 \pm 5,3$ & $105 \pm 5,3$ & $110 \pm 5,3$ & 0,53 & 0,57 \\
\hline LAD & $31,6 \pm 1,9$ & $30,8 \pm 1,9$ & $33 \pm 1,9$ & 0,91 & 0,43 \\
\hline LBD & $61 \pm 4,9$ & $61,1 \pm 4,9$ & $67 \pm 4,9$ & 0,62 & 0,41 \\
\hline TG & $57,1 \pm 6,2$ & $69,5 \pm 6,2$ & $53,6 \pm 6,2$ & 0,56 & 0,09 \\
\hline
\end{tabular}
in Pelibuey ewes, by treatment.

$1 \mathrm{~T}=$ dieta sin grasa adicional; $\mathrm{JC}=$ dieta con $1,5 \%$ de jabones de calcio de ácidos grasos; $\mathrm{S}=$ dieta con $1,2 \%$ de grasa bovina.

2 Contrastes: 1) T vs JC + S; 2) JC vs S.

$3 \mathrm{COL}=$ colesterol total; $\mathrm{LAD}=$ lipoproteínas de alta densidad; LBD $=$ lipoproteínas de baja densidad; TG = triglicéridos. 


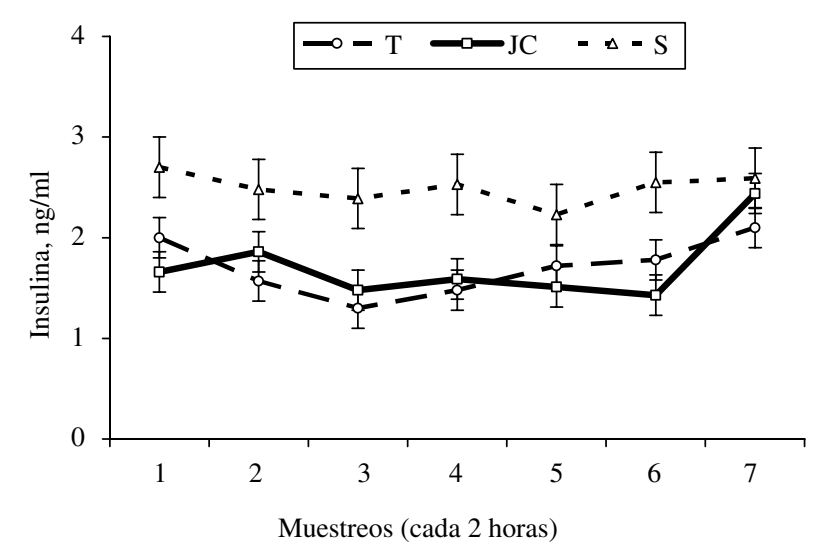

Figura 1. Concentración sérica de insulina en ovejas Pelibuey que consumieron una dieta testigo sin grasa adicional (T), con jabones de calcio de ácidos grasos (JC) o con grasa de bovino (S).

Serum insulin concentration in Pelibuey ewes that consumed a control diet without additional fat (T), a diet with calcium soap of fatty acids (JC) or one with bovine fat (S).

La suplementación de grasas afectó la concentración sérica de insulina (figura 1). La concentración media de insulina fue mayor $(\mathrm{P}<0,01)$ en las ovejas que consumieron grasa adicional en la dieta y superior $(\mathrm{P}<0,001)$ en aquellas suplementadas con grasa bovina $(2,5 \pm 0,11$ $\mathrm{ng} / \mathrm{ml}$ ) que en las ovejas alimentadas con la dieta testigo $(1,78 \pm 0,11 \mathrm{ng} / \mathrm{ml})$ o la que contenía JCAG $(1,72 \pm 0,11$ $\mathrm{ng} / \mathrm{ml})$.

La suplementación de grasa afectó la concentración sérica promedio de somatotropina (figura 2). Las ovejas alimentadas con la dieta que contenía grasa bovina (S) mostraron una concentración inferior de somatotropina $(\mathrm{P}<0,05)$ que las ovejas de los grupos JC y T $(2,2 \pm 0,15$; $2,6 \pm 0,15$ y $2,8 \pm 0,15$, respectivamente). Sin embargo, el número de pulsos registrados durante el periodo de muestreo y la magnitud de los mismos resultaron similares entre tratamientos $(P>0,05)$ como se muestra en el cuadro 3. En la figura 2 se puede ver también que la secreción de somatotropina durante el periodo de muestreo

Cuadro 3. Medias ( \pm EE) para el número y la amplitud de los pulsos de somatotropina en ovejas Pelibuey, por tratamiento.

Average $( \pm$ SE) number and amplitude of somatotropin pulses in Pelibuey ewes, by treatment.

\begin{tabular}{|c|c|c|c|c|c|}
\hline \multirow{2}{*}{ Pulsos de somatotropina } & \multicolumn{3}{|c|}{ Tratamiento $^{1}$} & \multicolumn{2}{|c|}{$\begin{array}{l}\text { Contraste }^{2}- \\
\text { valor de la P }\end{array}$} \\
\hline & $\mathrm{T}$ & $\mathrm{JC}$ & $S$ & 1 & 2 \\
\hline Número/12 horas & $0,2 \pm 0,2$ & $0,7 \pm 0,2$ & $1,0 \pm 0,2$ & 0,07 & 0,43 \\
\hline Amplitud, ng/ml & $3,3 \pm 0,8$ & $2,6 \pm 0,4$ & $2,1 \pm 0,4$ & 0,33 & 0,44 \\
\hline
\end{tabular}

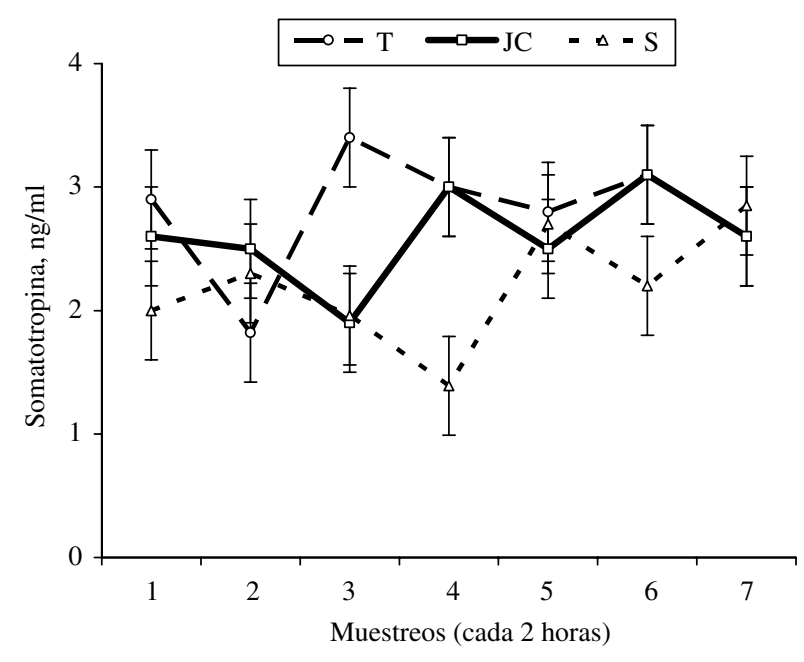

Figura 2. Concentración sérica de somatotropina en ovejas Pelibuey que consumieron una dieta testigo sin grasa adicional (T), con jabones de calcio de ácidos grasos (JC) o con grasa de bovino (S).

Somatotropin serum concentration in Pelibuey ewes that consumed a control diet without additional fat (T), a diet with calcium soap of fatty acids (JC) or one with bovine fat (S).

fue sumamente variable en lo que a la ocurrencia de los pulsos y su amplitud se refiere.

La concentración sérica de progesterona fue similar $(\mathrm{P}>0,05)$ entre tratamientos en el día 9 del ciclo estral $(3,3 \pm 0,43 ; 3,5 \pm 0,43$ y $4,4 \pm 0,43 \mathrm{ng} / \mathrm{ml}$ para el grupo $\mathrm{T}, \mathrm{S}$ y JC, respectivamente).

\section{DISCUSION}

Las dietas fueron balanceadas para ser isoenergéticas, por lo tanto se esperaba un consumo de energía similar entre tratamientos y que además el consumo de JCAG o de grasa bovina no afectara la fermentación ruminal. De acuerdo con los resultados observados en la dinámica del peso corporal, se puede especular que dichas suposiciones fueron cumplidas. Esta especulación se apoya en los resultados señalados por Elliot y col (1993) en donde no se determinaron diferencias en los coeficientes de digestibilidad de la materia seca, materia orgánica, celulosa, fibra detergente ácida, fibra detergente neutra y hemicelulosa al suplementar vacas lecheras con aceite de maíz en altas concentraciones, adicionado con grasa bovina a niveles de 2,5 o $5 \%$. Resultados similares se han reportado cuando se utilizan JCAG en proporciones superiores a las utilizadas en el presente estudio (Canale y col 1990).

Se considera que la similitud en las concentraciones de metabolitos de lípidos entre tratamientos puede ser debida a la baja proporción de grasa contenida en las dietas. Sin embargo, se han observado elevaciones de la concentración sérica de COL, LAD, LBD y TG en vacas para carne suplementadas en agostadero con una dieta que contenía solamente 1,25\% de JCAG (Espinoza 
y col 1995) y concentraciones elevadas de COL y TG en vacas Holstein suplementadas con una dieta conteniendo $2,5 \%$ de aceite vegetal (Marín-Aguilar y col 2007). Los resultados del presente estudio concuerdan con los reportados por López-Molina y col (1995) en lo que respecta a LBD cuando suplementaron ovejas Pelibuey con una dieta que contenía 5\% de JCAG. Sin embargo, a diferencia de lo observado en este estudio, las concentraciones de LAD y TG constatadas por ellos fueron más altas en las ovejas que consumieron JCAG. Las observaciones de la presente investigación también concuerdan con los resultados reportados por Carroll y col (1992) quienes observaron que los suplementos con alto contenido lipídico no modificaron las concentraciones plasmáticas de LBD.

Resulta oportuno especular que los resultados observados en las concentraciones de insulina podrían ser explicados por un contenido mayor de ácido oleico posiblemente presente en la dieta que incluyó la grasa bovina comparado con las otras dos, debido a que el consumo de grasas que contienen ácido oleico y linoleico incrementa la producción de propionato en el rumen (Chalupa y col 1986). En las ovejas, el propionato puede influir sobre los niveles plasmáticos de insulina (Sano y col 1995 ${ }^{\mathrm{a}}$ ) independientemente de ser un precursor de la gluconeogénesis hepática (Fahey y Berger 1988), ya que las células $\beta$ del páncreas son sensibles al ácido graso señalado (Sano y col $1995^{\mathrm{b}}$ ). Esto puede explicar la mayor diferencia entre los tratamientos en la concentración sérica de insulina observada al inicio del periodo de muestreo con respecto al final de dicho periodo, ya que probablemente la disponibilidad y absorción ruminal de propionato y otros ácidos grasos volátiles como el butirato que también promueve la secreción de insulina (Sano y col 1995 ${ }^{\mathrm{b}}$ ) fueron mayores cuando se colectó la primera muestra de sangre y se redujeron conforme se prolongó el ayuno de los animales.

Existe poca consistencia en los resultados de investigación en relación al efecto de la grasa de la dieta sobre la concentración sérica de somatotropina. En la mayoría de los casos la suplementación de grasas a vacas lecheras no ha influido, o ha reducido los niveles sanguíneos de la hormona señalada (Gagliostro y col 1991). Lo anterior se debe probablemente a que en los animales que consumen grasas el balance energético es más eficiente y dichos animales eliminan la somatotropina de una manera más intensa (Trenkle 1970).

Evidencias similares a las obtenidas para la concentración de progesterona en este trabajo fueron reportadas en ovejas Pelibuey suplementadas con $50 \mathrm{~g}$ oveja/día de JCAG (López-Molina y col 1995) y en vacas Holstein suplementadas con 2,5\% de aceite vegetal durante el periodo posparto (Marín-Aguilar y col 2007). En el presente estudio, la similitud entre tratamientos observada en la concentración sérica de progesterona tal vez estuvo originada por los niveles parecidos de COL, LAD y LBD, ya que en la mayoría de las especies está demostrado que los niveles aumentados de LAD y de LBD incrementan la producción de progesterona por parte del cuerpo lúteo (Carroll y col 1992), señalándose también que, además de participar en el aporte de COL, las lipoproteínas contribuyen en la estimulación directa de la secreción del factor de crecimiento similar a la insulina tipo I por las células lúteas, factor que es importante en la esteroidogénesis (Galvis y col 2005).

De acuerdo con los resultados obtenidos en el presente estudio se concluye que el uso de grasa bovina o de jabones de calcio de ácidos grasos en la dieta de ovejas Pelibuey, incluidos en proporciones de 1,2 y $1,5 \%$ de la materia seca consumida, respectivamente, no afecta la ganancia de peso, las concentraciones séricas de metabolitos de lípidos y de progesterona. Sin embargo, la concentración sérica de insulina se incrementó y la de somatotropina se redujo con el consumo de grasa bovina.

\section{RESUMEN}

Se utilizaron ovejas Pelibuey multíparas para determinar la influencia de los jabones de calcio de ácidos grasos (JCAG) y de la grasa bovina en la dieta sobre la concentración sérica de insulina, somatotropina, progesterona y metabolitos de los lípidos (colesterol total, lipoproteínas de alta densidad, lipoproteínas de baja densidad y triglicéridos). Las ovejas ( $\mathrm{n}=6$ por grupo) se asignaron aleatoriamente a una dieta que contenía $1,5 \%$ de JCAG (JC), 1,2\% de grasa bovina (S) o a una dieta testigo (T) sin grasa adicional. Las dietas se proporcionaron durante 75 días. La ganancia de peso fue similar entre tratamientos $(\mathrm{P}>0,05)$. La concentración de metabolitos de lípidos y de progesterona no estuvieron afectadas por la dieta $(\mathrm{P}>0,05)$. La concentración de insulina fue mayor $(\mathrm{P}<0,01)$ en ovejas que consumieron grasa adicional y superior $(\mathrm{P}<0,001)$ en $\mathrm{S}$ que en $\mathrm{T}$ y JC. La concentración de somatotropina fue más baja $(\mathrm{P}<0,05)$ en las ovejas de los grupos JC y $\mathrm{S}$ que en $\mathrm{T}$. El número de pulsos de somatotropina y su amplitud fueron similares entre tratamientos $(\mathrm{P}>0,05)$. Se concluye que la grasa bovina y los jabones de calcio de ácidos grasos incorporados en las dietas de ovejas Pelibuey en los tipos y las proporciones señaladas no afectan la ganancia de peso, la concentración de progesterona ni de los metabolitos de los lípidos, pero la grasa de bovino incrementó el nivel sérico de insulina y redujo la somatotropina.

\section{REFERENCIAS}

AOAC. Association of Official Analytical Chemists. 1995. Official Methods of Analysis. $16^{\text {th }}$ ed. AOAC, Arlington, VA, USA.

Canale CJ, PL Burgess, LD Muller, GA Varga. 1990. Calcium salts of fatty acids in diets that differ in neutral detergent fiber: effect on lactation performance and nutrient digestibility. J Dairy Sci 73, 1031-1038.

Carroll DJ, RR Grummer, MK Clayton. 1992. Stimulation of luteal cell progesterone production by lipoproteins from cows fed control or fat-supplemented diets. J Dairy Sci 75, 2205-2214.

Chalupa W, B Veechiarelli, AE Esler, DS Kronfeld, D Sklan, DL Palmquist. 1986. Ruminal fermentation in vivo as influenced by long-chain fatty acids. J Dairy Sci 69, 1293-1301.

DGTENAL, Dirección General de Geografía del Territorio Nacional. 1980. Carta Topográfica. La Paz, Baja California Sur, México.

Elliott JP, JK Drackley, DJ Schauff, EH Jaster. 1993. Diets containing high oil corn and tallow for dairy cows during early lactation. $J$ Dairy Sci 76, 775-789.

Espinoza JL, JA Ramírez-Godínez, J Jiménez, A Flores. 1995. Effects of calcium soaps of fatty acids on postpartum reproductive activity in beef cows and growth of calves. J Anim Sci 73, 2888-1892. 
Espinoza JL, JA Ramírez-Godínez, SS Simental, J Jiménez, R Ramírez, A Palacios, R de Luna. 1997. Effects of calcium soaps of fatty acids on serum hormones and lipid metabolites in Pelibuey ewes. Small Ruminant Res 26, 61-68.

Espinoza JL, O López-Molina, JA Ramírez-Godínez, J Jiménez, A Flores. 1998. Milk composition, postpartum reproductive activity and growth of lambs in Pelibuey ewes fed calcium soaps of long chain fatty acids. Small Ruminant Res 27, 119-124.

Fahey GC, LL Berger. 1988. Carbohydrate nutrition of ruminants. In: Church DC (ed). The Ruminant Animal, Digestive Physiology and Nutrition. Prentice Hall, New Jersey, USA, Pp 269-297.

Gagliostro G, Y Chilliard, M Davicco. 1991. Duodenal rapeseed oil infusion in early and mid lactating cows. 3. Plasma hormones and apparent mammary uptake of metabolites. J Dairy Sci 74, 1893-1903.

Galvis RD, HJ Correa, NF Ramírez. 2005. Interacciones entre el balance nutricional, los indicadores del metabolismo energético y proteico y las concentraciones plasmáticas de insulina y IGF-I en vacas en la lactancia temprana. Rev Colomb Cienc Pec 16, 237-248.

Gong JG, TA Bramley, R Webb. 1993. The effect of recombinant bovine somatotropin on ovarian function in heifers: follicular populations and peripheral hormones. Biol Reprod 45, 941-949.

Grummer RR, DJ Carroll. 1988. A review of lipoprotein cholesterol metabolism: importance to ovarian function. J Anim Sci 66, 3160-3173.

Hawkins DE, KD Niswender, GM Oss, CL Moeller, KG Odde, HR Sawyer, GD Niswender. 1995. An increase in serum lipids increases luteal lipid content and alters the disappearance rate of progesterone in cows. J Anim Sci 72, 541-545.

Hightshoe RB, RC Cochran, LR Corah, GH Kiracofe, DL Harmon, RC Perry. 1991. Effects of calcium soaps of fatty acids on postpartum reproductive function in beef cows. J Anim Sci 69, 4097-4103.

Hoefler WC, DM Hallford. 1987. Influence of suckling status estrus and type of birth on serum hormone profiles and return to estrus in earlypostpartum spring-lambing ewes. Theriogenology 27, 877-895.

Langhout DJ, LJ Spicer, RD Geisert. 1991. Development of a culture system for bovine granulosa cells: effects of growth hormone, estradiol and gonadotropins on cell proliferation, steroidogenesis, and protein synthesis. J Anim Sci 69, 3321-3334.

López-Molina O, JA Ramírez-Godínez, J Jiménez, A Flores, JL Espinoza. 1995. Effects of calcium soaps of fatty acids on milk composition, fat metabolites and reproductive performance in Pelibuey ewes. Proc Western Section, Amer Soc Anim Sci 46, 157-160.

Marín-Aguilar AM, JC Tinoco-Magaña, J Herrera-Camacho, LG SánchezGil, VM Sánchez-Parra, JL Solorio-Rivera, A García-Valladares. 2007. Reinicio de la actividad ovárica y nivel de metabolitos de lípidos en vacas lecheras suplementadas con aceite vegetal durante el posparto temprano. Interciencia 32, 180-184.

NRC, National Research Council. 1985. Nutrient Requirements of Sheep. $6^{\text {th }}$ ed. National Academy Press, Washington, DC, USA.

Sano H, S Hayakawa, H Takahashi, Y Terashima. 1995ª Plasma insulin and glucagon responses to propionate infusion into femoral and mesenteric veins in sheep. J Anim Sci 73, 191-197.

Sano H, S Tano, H Takahashi, Y Terashima. 1995 ${ }^{\mathrm{b}}$. Dose response of plasma insulin and glucagon to intravenous n-butirate infusion in sheep. J Anim Sci 73, 3038-3043.

Sanson DW, DM Hallford. 1984. Growth response, carcass characteristics and serum glucose and insulin in lambs fed tolazamide. Nutr Rep Int 29, 461-471.

SAS USER'S GUIDE: Statistics. Version 1989. SAS Inst. Inc., Cary, NC, USA.

Thomas MG, B Bao, GL Williams. 1997. Dietary fats varying in their fatty acids composition differentially influence follicular growth in cows fed isoenergetic diets. J Anim Sci 75, 2512-2519.

Trenkle A. 1970. Effects of short chain fatty acids, feeding, fasting, and type of diet on plasma insulin levels in sheep. $J$ Nutr 100 , 1323-1330.

Walters DL, D Schams, E Schallenberger. 1984. Pulsatile secretion of gonadotrophins, ovarian steroids and ovarian oxytocin during the luteal fase of the estrous cycle in the cow. J Reprod Fert 71, 479-491.

Wehrman ME, GL Williams. 1989. Effect of dietary lipid intake on serum and ovarian follicular lipid metabolites and follicular populations in beef females. J Anim Sci 67 ( Suppl. 1), 59 (Abstr.). 